\title{
Comparison of different surgical interventions for hepatocellular carcinoma with bile duct tumor thrombus: a systematic review and meta-analysis
}

\author{
Jin-Kai Feng ${ }^{1 \#}$, Zhen-Hua Chen ${ }^{2 \#}$, Yu-Xuan Wu ${ }^{3 \#}$, Kang Wang ${ }^{1}, J_{u}-X i a n$ Sun $^{1}$, Zong-Tao Chai ${ }^{1}$, \\ Wei-Xing Guo ${ }^{1}$, Jie Shi ${ }^{1}$, Shu-Qun Cheng ${ }^{1}$ \\ ${ }^{1}$ Department of Hepatic Surgery VI, Eastern Hepatobiliary Surgery Hospital, Second Military Medical University, Shanghai, China; ${ }^{2}$ Department \\ of General Surgery, Zhejiang Provincial Armed Police Corps Hospital, Hangzhou, China; ${ }^{3}$ School of Basic Medicine, Second Military Medical \\ University, Shanghai, China \\ Contributions: (I) Conception and design: SQ Cheng, JK Feng, ZH Chen, YX Wu; (II) Administrative support: SQ Cheng; (III) Provision of study \\ materials or patients: K Wang, JX Sun, ZT Chai, WX Guo, J Shi; (IV) Collection and assembly of data: JK Feng, ZH Chen; (V) Data analysis and \\ interpretation: JK Feng, ZH Chen, YX Wu; (VI) Manuscript writing: All authors; (VII) Final approval of manuscript: All authors. \\ "These authors have contributed equally to this work. \\ Correspondence to: Shu-Qun Cheng, MD, PhD. Eastern Hepatobiliary Surgery Hospital, Second Military Medical University, 225 Changhai Road, \\ Shanghai 200433, China. Email: chengshuqun@aliyun.com.
}

Background: The optimal surgical modality for hepatocellular carcinoma (HCC) with bile duct tumor thrombus (BDTT) remains controversial, especially regarding deciding whether to perform concurrent bile duct resection (BDR).

Methods: PubMed, EMBASE, Cochrane Library, Web of Science and Scopus databases were systematically searched from inception to February 2020, in order to compare overall survival (OS) and recurrence-free survival (RFS) rates of HCC patients with BDTT who had either received hepatectomy with extrahepatic bile duct resection (BDR group) or hepatectomy without bile duct resection (NBDR group). Relevant outcomes were extracted by two investigators.

Results: A total of 12 studies involving 355 patients was included. The 1-, 3- and 5-year OS rates were similar in the BDR and NBDR groups (OR =0.58, 95\% CI: 0.31-1.09, P=0.09; OR =0.74, 95\% CI: 0.43-1.28, $\mathrm{P}=0.28$; OR $=0.63$, 95\% CI: 0.36-1.11, $\mathrm{P}=0.11$, respectively). However, the BDR group had better 1-, 3and 5-year RFS rates than the NBDR group (OR =0.38, 95\% CI: $0.22-0.65, \mathrm{P}<0.01$; OR $=0.40,95 \% \mathrm{CI}$ : $0.22-0.72, \mathrm{P}<0.01 ; \mathrm{OR}=0.37,95 \% \mathrm{CI}: 0.19-0.71, \mathrm{P}<0.01$, respectively).

Conclusions: Concomitant bile duct resection results in decreased postoperative recurrence in HCC patients with BDTT. However, the OS rates were similar whether or not patients underwent bile duct resection.

Keywords: Hepatocellular carcinoma (HCC); bile duct tumor thrombus (BDTT); bile duct resection (BDR); meta-analysis

Submitted May 14, 2020. Accepted for publication Oct 18, 2020.

doi: 10.21037/atm-20-3935

View this article at: http://dx.doi.org/10.21037/atm-20-3935

\section{Introduction}

Hepatocellular carcinoma (HCC) ranks as the sixth most commonly diagnosed cancer and the fourth leading cause of tumor-related death worldwide (1). HCC often invades into vascular systems to form portal vein or hepatic vein tumor thrombus, leading to intrahepatic dissemination and distant spread $(2,3)$. HCC can also extend into bile duct branches and subsequently result in bile duct tumor thrombus (BDTT). BDTT is seen in $0.5-12.9 \%$ of surgical specimens of HCC (4). Current data indicate that surgical 
resection leads to a more favorable survival outcome than nonsurgical treatments or supportive care (5-7). However, due to the low incidence of BDTT caused by HCC, only a few studies have focused on this special disease entity, and clinical decisions regarding surgical modalities for removing BDTT mostly depend on surgeons' personal preferences and experience.

Some studies reported no significant differences in overall survival (OS) or recurrence-free survival (RFS) of HCC patients with BDTT whether or not they underwent extrahepatic bile duct resection $(7,8)$. However, other investigators reported that BDR contributed to significantly better long-term survival of HCC patients with BDTT $(9,10)$. Hence, the optimal surgical choice and the necessity of BDR for patients with HCC and BDTT remains unclear.

Hence, we conducted the first meta-analysis to compare OS and RFS rates of patients with concomitant HCC and BDTT who underwent BDR versus those who did not undergo BDR. Furthermore, our review team summarized the potential benefits and risks of the two distinct surgical methods, which may provide clinical guidance for selecting the appropriate treatment and assist in rational decisionmaking. We present the following article in accordance with the Preferred Reporting Items for Systematic Reviews and Meta-Analyses (PRISMA) checklist (11) (available at http:// dx.doi.org/10.21037/atm-20-3935).

\section{Methods}

\section{Literature search and selection}

We conducted a comprehensive literature search of online databases including PubMed, EMBASE, Cochrane Library, Web of Science and Scopus from inception up to February 1, 2020 to identify all relevant articles. Medical Subject Headings (MeSH) terms and free-text terms were used in combination as the search strategy. The $\mathrm{MeSH}$ terms were as follows: "carcinoma, hepatocellular" AND "bile duct thrombus". The free-text terms were as follows: "hepatocellular carcinoma" OR "liver cancer" OR "hepatic cancer" OR "liver neoplasm" OR "liver tumor" OR "hepatic tumor" OR "hepatocarcinoma" OR "liver cell carcinoma" OR "HCC" OR "hepatoma" AND "bile duct tumor thromb" OR "bile duct tumour thromb" OR "biliary tumor thromb" OR "biliary tumour thromb" OR "bile duct invasion" OR "biliary invasion". References of the retrieved articles were reviewed carefully and searched manually to identify additional studies. The retrieved articles were then imported to Endnote X9 software for further screening.

\section{Selection criteria}

The inclusion criteria were as follows: study population: patients with histopathologically confirmed HCC and BDTT; intervention: hepatectomy plus extrahepatic bile duct resection (BDR group) versus liver resection alone or hepatectomy combined with thrombectomy (NBDR group); study design: randomized controlled trials (RCTs) or observational studies including case-control and cohort studies; outcome measures: overall survival (OS) and recurrence-free survival (RFS).

The exclusion criteria were as follows: (I) non-HCC; (II) recurrent or secondary HCC; (III) patients who had undergone adjuvant therapy other than surgery; (IV) patients who had undergone liver transplantation; (V) reports focusing on diagnostic techniques of BDTT; (VI) basic experimental studies involving BDTT; (VII) no survival outcomes reported; (VIII) full-text articles not available; (IX) case reports, conference abstracts, narrative reviews, comments or other documents unrelated to the topic.

\section{Data extraction and quality assessment}

Data extraction and evaluation of methodological quality of the included articles were conducted independently by two investigators (Feng JK, Chen ZH). Any disagreement was resolved by another investigator ( $\mathrm{Wu} \mathrm{YX}$ ). A predefined Microsoft Excel spreadsheet was used to record all relevant information, including the baseline characteristics (first author, year and country of publication, inclusion period, study design, sample size, age and gender of patients), the classification of BDTT, and the primary outcomes (1-, 3-, 5-year OS rates and 1-, 3-, 5-year RFS rates).

BDTT was mainly categorized using the methods proposed by Satoh et al. (12), in which type III suggests that BDTT is separated from the primary tumor and floats into the common bile duct. In addition, BDTT was classified based on the principles recommended by Ueda et al. (13) in one study and by the Liver Cancer Study Group of Japan (LCSGJ) (14) in another study. OS was defined as the time interval from the date of surgery to the date of death. RFS was defined as the time interval from the date of surgery to the date when a recurrent tumor or BDTT was first diagnosed.

For quality evaluation of the included studies, RCTs 


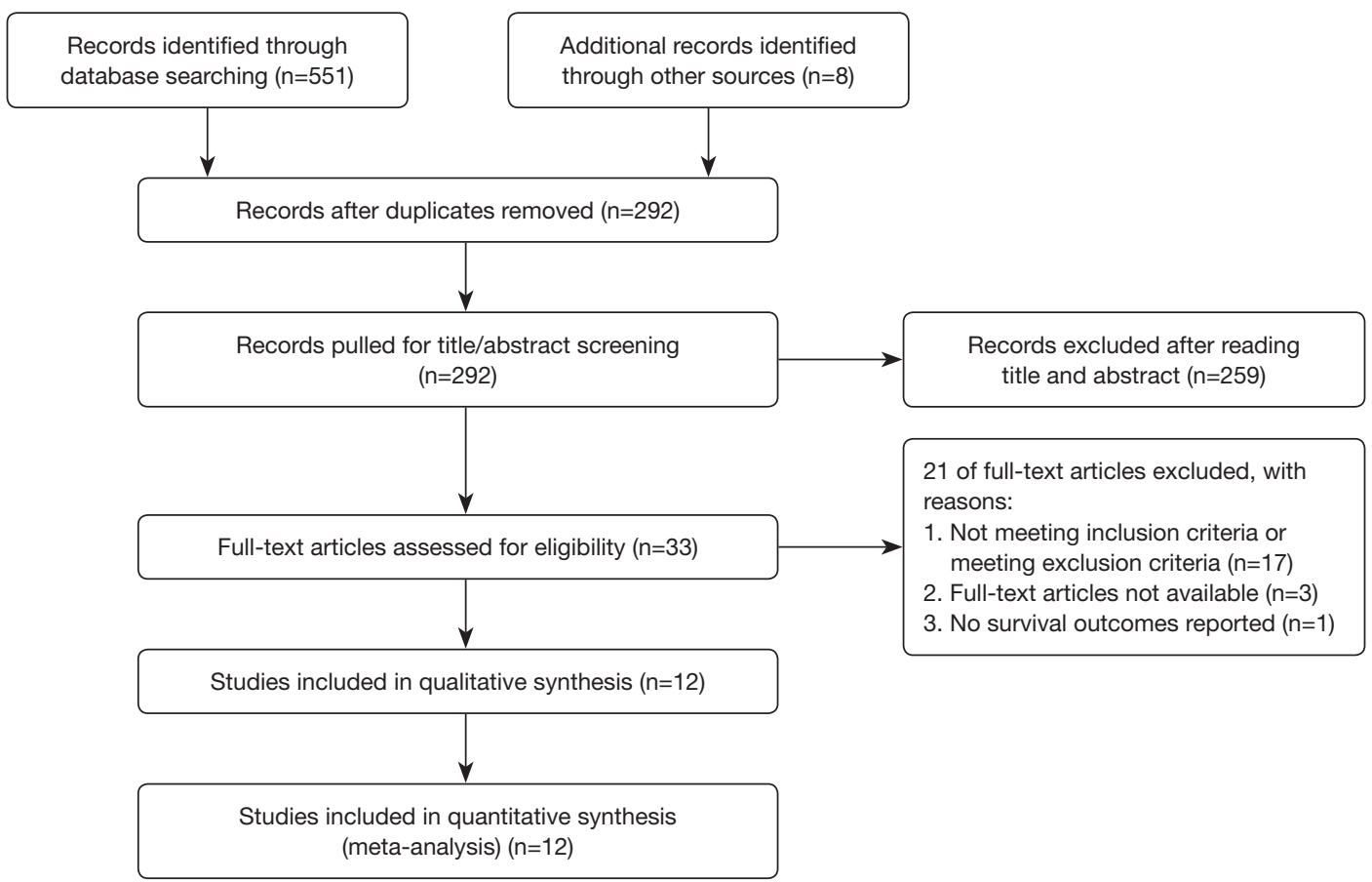

Figure 1 PRISMA flow diagram of the process for identifying eligible studies.

were assessed using the Cochrane Collaboration's tool (15). The modified Newcastle-Ottawa Scale (NOS) was utilized to assess the quality of observational studies (16).

\section{Statistical analysis}

The pooled odds ratios (ORs) with $95 \%$ confidence intervals (CIs) were estimated using a generic MantelHaenszel model for OS and RFS. If the survival outcomes could not be obtained directly from the published studies, the survival (or recurrence) status and the corresponding time to death (or relapse) were recorded, and the program GraphPad Prism (Version 8.2.0) was used to calculate these values. Cumulative meta-analyses were also performed to assess the stability of the effect sizes. Heterogeneity among studies was examined using the Chi-square test and $\mathrm{I}^{2}$ statistic, with $\mathrm{I}^{2}>50 \%$ indicating significant heterogeneity and $\mathrm{I}^{2} \leq 50 \%$ suggesting slight heterogeneity (17). The estimates were pooled with a random-effects model if significant heterogeneity was identified; otherwise, a fixedeffects model was applied. Publication bias was qualitatively detected using Funnel plots, and quantitatively assessed by Begg's and Egger's tests (18). Sensitivity analyses were further performed to determine the robustness of overall estimates. Statistical significance was set at a $P$ value less than 0.05 (2-tailed). All the statistical analyses were performed using the program Stata (Version 12.0, Stata Corp LP, College Station, TX, USA).

\section{Results}

\section{Study selection and quality assessment}

Based on the search strategy described in Methods above, 551 citations were extracted from the online databases. Eight publications were identified through manually searching the reference lists of the retrieved articles. After removing duplicates, 292 records remained. Of these, 259 records were excluded according to the selection criteria following reading of the titles and abstracts. Among the remaining 33 records, 21 were removed for various other reasons. Eventually, 12 studies were eligible for this metaanalysis (7-10,12,19-25) (Figure 1). Their scores for the quality assessment are summarized in Table 1 . All studies achieved 5 to 8 points on a scale of $0-9$. A summary of the detailed risk of bias for each study is shown in Figure S1.

\section{Patients' characteristics}

All basic information of the included studies and the baseline characteristics of the patients are presented in 
Table 1 Characteristics and methodological quality of the included studies

\begin{tabular}{|c|c|c|c|c|c|c|c|c|c|c|}
\hline Study & Year & Country & Intervention & $\begin{array}{l}\text { Inclusion } \\
\text { period }\end{array}$ & $\begin{array}{l}\text { Study } \\
\text { design }\end{array}$ & $\begin{array}{c}\text { Number of } \\
\text { patients }\end{array}$ & $\begin{array}{l}\text { Mean age } \\
\text { (year) }\end{array}$ & $\begin{array}{l}\text { Gender } \\
\text { (Male\%) }\end{array}$ & $\begin{array}{l}\text { BDTT type } \\
\text { (Satoh III\%) }\end{array}$ & $\begin{array}{l}\text { Quality } \\
\text { Score }\end{array}$ \\
\hline Wang et al. & 1999 & Korea & \multirow{3}{*}{$\begin{array}{l}\text { Hepatectomy } \\
\text { plus BDR } \\
\text { versus } \\
\text { Hepatectomy } \\
\text { without BDR }\end{array}$} & 1994-1998 & NRCT & $4 / 2$ & N/A & $\mathrm{N} / \mathrm{A}$ & N/A & 5 \\
\hline Peng et al. & 2004 & China & & 1994-2002 & NRCT & $1 / 6$ & $49.0 / 51.6$ & $100.0 / 83.3$ & $0 / 33.3$ & 5 \\
\hline Esaki et al. & 2005 & Japan & & 1990-2002 & NRCT & $8 / 30$ & $59.5 / 59.8$ & N/A & $40.0 / 7.1$ & 7 \\
\hline Moon et al. & 2013 & Korea & & 1989-2011 & NRCT & $31 / 42$ & N/A & $\mathrm{N} / \mathrm{A}$ & $77.4 / 35.7^{\ddagger}$ & 7 \\
\hline Oba et al. & 2014 & Japan & & 1992-2012 & NRCT & $6 / 7$ & $61.8 / 59.6$ & $83.3 / 100.0$ & $\mathrm{~N} / \mathrm{A}$ & 6 \\
\hline Kasai et al. & 2015 & Japan & & 1988-2013 & NRCT & $7 / 37$ & $\mathrm{~N} / \mathrm{A}$ & $\mathrm{N} / \mathrm{A}$ & $\mathrm{N} / \mathrm{A}$ & 5 \\
\hline Kim et al. & 2018 & $\begin{array}{l}\text { Japan/ } \\
\text { Korea }\end{array}$ & & 1992-2014 & NRCT & $44 / 49$ & N/A & $\mathrm{N} / \mathrm{A}$ & $\mathrm{N} / \mathrm{A}$ & 8 \\
\hline Lin et al. & 2019 & China & & 2004-2018 & NRCT & $2 / 4$ & $32.5 / 48.3$ & $\mathrm{~N} / \mathrm{A}$ & N/A & 6 \\
\hline
\end{tabular}

Data were described as BDR/NBDR in most blanks. ${ }^{\dagger}$, the age was expressed as median. BDTT type was clarified based on Satoh's classification except for otherwise stated. ${ }^{\ddagger}$, this was classified based on Ueda's classification and displayed the percentage of type 3 within types 2 and $3 .{ }^{\S}$, this was categorized according to the classification algorithm proposed by the Liver Cancer Study Group of Japan (LCSGJ) and presented the percentage of type B4 within types B3 and B4. BDTT, bile duct tumor thrombus; BDR, bile duct resection; $\mathrm{NRCT}$, nonrandomized controlled trial; N/A, data not available.

Table 1. In total, $355 \mathrm{HCC}$ patients with BDTT were included, of whom 128 (36.1\%) received concurrent BDR and $227(63.9 \%)$ were assigned to the NBDR group. The predominant gender of patients was male, accounting for $83.3 \%$ and $79.1 \%$ of the BDR and NBDR groups, respectively. Furthermore, we noted that the percentage of patients with BDTT of type III or B4 classification was basically higher in the BDR group, suggesting that combined BDR was more frequently performed when HCC was complicated by a more advanced grade of BDTT. Additional details are given in Table 1.

\section{Overall survival}

As shown in Table 2 and Figure 2, ten studies were included in the meta-analyses of the 1-, 3-, and 5-year OS rates and the corresponding ORs for OS. The 1-year OS rate was not statistically significantly different between the BDR and NBDR groups $(81.7 \%$ vs. $69.5 \%, \mathrm{OR}=0.58,95 \%$ CI: $0.31-1.09, \mathrm{I}^{2}=25 \%$; Figure $2 A$ ). Similar results were obtained for the 3 -year OS rate $(52.4 \%$ vs. $40.2 \%$, OR $=0.74,95 \%$ CI: $0.43-1.28, \mathrm{I}^{2}=39 \%$; Figure $2 C$ ) and the 5 -year OS rate
(45.1\% vs. $31.6 \%$, OR $=0.63,95 \%$ CI: $0.36-1.11, \mathrm{I}^{2}=28 \%$; Figure 2E). Cumulative meta-analyses of the 1-, 3-, and 5-year OS rates demonstrated that the $95 \%$ CIs gradually narrowed as subsequent studies were added and the effect sizes became stable (Figure 2B,D,F). The meta-analyses of pooled OR for OS showed that HCC patients with BDTT who underwent hepatectomy combined with extrahepatic BDR had an OS similar to those who received liver resection alone or hepatectomy plus thrombectomy without additional BDR.

\section{Recurrence-free survival}

As shown in Table 2 and Figure 3, six studies were included in the meta-analyses of the 1-, 3-, and 5-year RFS rates and the corresponding ORs for RFS. The 1-year RFS rate in the BDR group was significantly higher than that in the NBDR group $(67.0 \%$ vs. $40.8 \%$, OR $=0.38,95 \%$ CI: $0.22-0.65, \mathrm{I}^{2}=0 \%$; Figure $3 A$ ). Similar results were obtained for the 3 -year RFS rate ( $42.3 \%$ vs. $21.8 \%$, OR $=0.40,95 \%$ CI: $0.22-0.72, \mathrm{I}^{2}=0 \%$; Figure $3 C$ ) and the 5 -year RFS rate (33.0\% vs. $15.5 \%$, OR $=0.37,95 \%$ CI: $0.19-0.71, \mathrm{I}^{2}=10 \%$; Figure $3 E$ ). The results of cumulative-meta analyses showed 
Table 2 Summary of meta-analysis for long-term survival outcomes of HCC patients with BDTT

\begin{tabular}{|c|c|c|c|c|c|}
\hline \multirow{2}{*}{$\begin{array}{l}\text { Long-term survival outcomes } \\
\text { (number of studies) }\end{array}$} & \multicolumn{2}{|c|}{ Survival rate (\%) } & \multirow{2}{*}{ Pooled OR $(95 \% \mathrm{Cl})$} & \multirow{2}{*}{$\mathrm{P}$} & \multirow{2}{*}{ Heterogeneity $\left(\chi^{2} / \mathrm{P} / \mathrm{I}^{2}\right.$} \\
\hline & BDR & NBDR & & & \\
\hline \multicolumn{6}{|l|}{ Overall survival } \\
\hline 1-year OS [10] & 81.7 & 69.5 & $0.58(0.31-1.09)$ & 0.09 & $11.92 / 0.22 / 25 \%$ \\
\hline 3-year OS [10] & 52.4 & 40.2 & $0.74(0.43-1.28)$ & 0.28 & $14.76 / 0.10 / 39 \%$ \\
\hline \multicolumn{6}{|l|}{ Recurrence-free survival } \\
\hline 1-year RFS [6] & 67.0 & 40.8 & $0.38(0.22-0.65)$ & $<0.01^{*}$ & $4.90 / 0.43 / 0 \%$ \\
\hline 3-year RFS [6] & 42.3 & 21.8 & $0.40(0.22-0.72)$ & $<0.01^{*}$ & $4.47 / 0.48 / 0 \%$ \\
\hline 5-year RFS [6] & 33.0 & 15.5 & $0.37(0.19-0.71)$ & $<0.01^{*}$ & $5.58 / 0.35 / 10 \%$ \\
\hline
\end{tabular}

*, P values with statistical significance. HCC, hepatocellular carcinoma; BDTT, bile duct tumor thrombus; BDR, hepatectomy plus bile duct resection; NBDR, liver resection alone or hepatectomy plus thrombectomy without bile duct resection; OR, odds ratio; $\mathrm{Cl}$, confidence interval; OS, overall survival; RFS, recurrence-free survival.

that statistically significant differences in favor of the BDR group were initially observed in the 4th study in 2016 (Figure 3B), the 5th study in 2018 (Figure 3D), and the 5th study in 2018 (Figure $3 F$ ), with the $95 \%$ CIs narrowing and the effect sizes becoming stable. The meta-analyses of pooled OR for RFS revealed that RFS was significantly better for HCC patients with BDTT in the BDR group than in the NBDR group.

\section{Subgroup analysis}

Considering that those studies with small sample sizes might introduce high-risk bias and affect the reliability of the results, we divided the included studies into two groups on the basis of the overall sample size ( $<20 v s . \geq 20$ cases). With respect to the 1-, 3-, and 5-year OS of patients assigned to these two groups, the subtotal outcomes in each showed consistency relative to the overall outcomes. Regarding the 1-, 3-, and 5-year RFS, although there was no statistically significant difference for the subsets containing less than 20 patients, the subsets with $\geq 20$ patients showed the same tendency as the corresponding overall groups (Figure S2).

\section{Publication bias and sensitivity analysis}

Funnel plots of the 1-, 3-, and 5-year OS and RFS rates are presented in Figure S3. A visual inspection of the funnel plots indicated a symmetrical distribution. Begg's and Egger's tests confirmed that there was no potential publication bias among these studies (Figure S3). Sensitivity analyses of the
1-, 3-, and 5-year OS and RFS rates were performed by excluding each of the studies one by one, which confirmed the stability and robustness of the results (Figure S4).

\section{Discussion}

To the best of our knowledge, our study is the first systematic review and meta-analysis to compare the OS and RFS rates between HCC patients with BDTT who underwent or did not undergo additional BDR. We reviewed 12 studies involving 355 patients with HCC and BDTT, which as far as we are aware, is the largest sample size analyzed to date in this context. All the studies included were NRCTs because the intrinsic nature of the procedure means that it is difficult to conduct prospective randomized controlled trials. Nonetheless, we confirmed the relatively high quality of most included studies by quality assessment and publication bias testing. In addition, there was no significant heterogeneity measurable on all of the survival outcomes across studies. Sensitivity analyses also suggested that the overall effect sizes were not affected by each individual study.

BDTT resulting from HCC, also termed "icteric type of hepatoma", is a special condition recognized in clinical practice (26). Obstructive jaundice is frequently observed in these patients when BDTT involves the main biliary tract (22,27-29). Aggressive surgical intervention is considered to be contraindicated at the initial period for this group of patients because of impaired hepatic functional reserve secondary to underlying cirrhosis or severe cholestasis. Surgical treatments carry a high risk of postoperative 
A Study$$
\text { ID }
$$

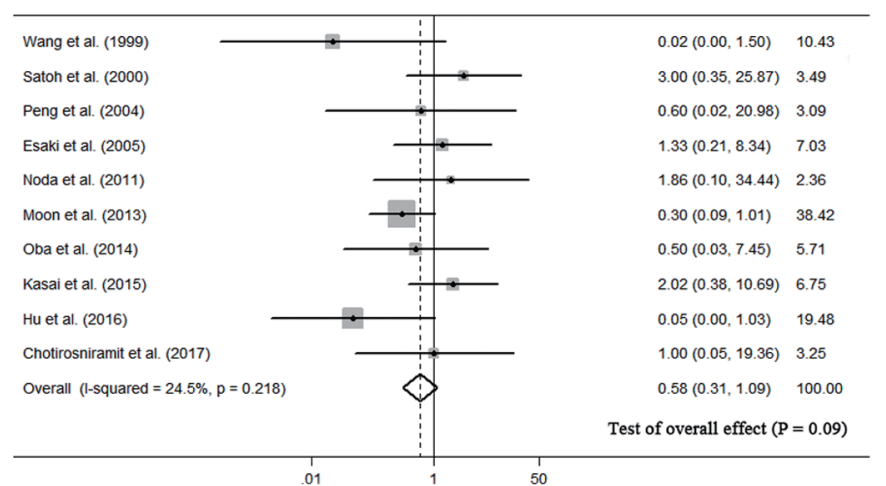

\section{C}

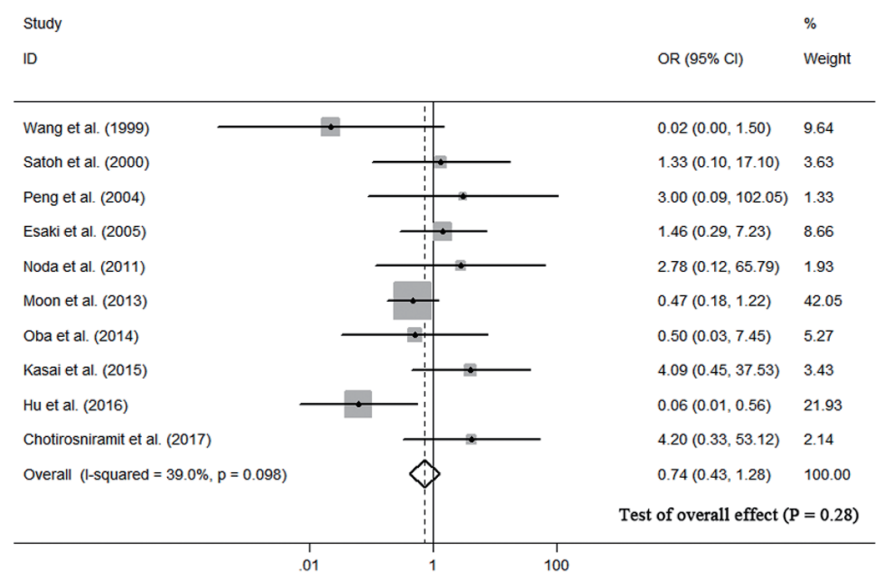

\section{$\mathrm{E}$}

$$
\text { Study }
$$

\section{Wang et al. (1999)}

ID

Satoh et al. (2000)

Peng et al. (2004)

Esaki et al. (2005)

Noda et al. (2011)

Moon et al. (2013)

Oba et al. (2014)

Kasai et al. (2015)

Hu et al. (2016)

Chotirosniramit et al. (2017)

Overall (I-squared $=27.6 \%, p=0.190$ )

.01

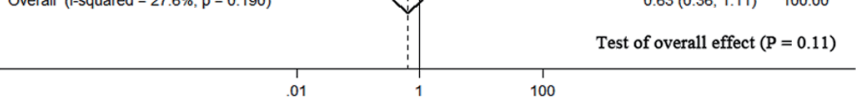

B

Study

ID

\begin{tabular}{|c|c|}
\hline Wang et al. (1999) & $0.02(0.00,1.50)$ \\
\hline Satoh et al. (2000) & $0.77(0.17,3.53)$ \\
\hline Peng et al. (2004) & $0.74(0.18,2.99)$ \\
\hline Esaki et al. (2005) & $0.91(0.30,2.79)$ \\
\hline Noda et al. (2011) & $1.00(0.35,2.82)$ \\
\hline Moon et al. (2013) & $0.58(0.27,1.26)$ \\
\hline Oba et al. (2014) & $0.57(0.27,1.21)$ \\
\hline Kasai et al. (2015) & $0.70(0.36,1.37)$ \\
\hline Hu et al. (2016) & $0.57(0.30,1.08)$ \\
\hline Chotirosniramit et al. (2017) & $0.58(0.31,1.09)$ \\
\hline
\end{tabular}

D

ID

OR $(95 \% \mathrm{Cl})$

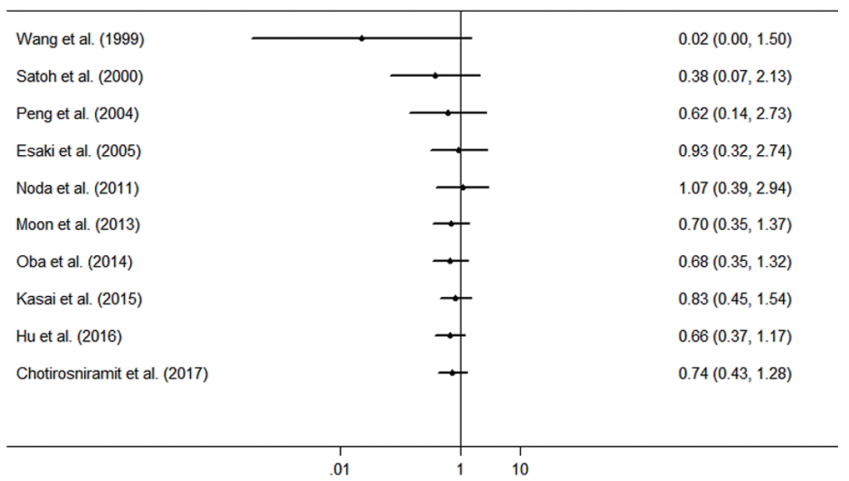

$\mathrm{F}$

Study

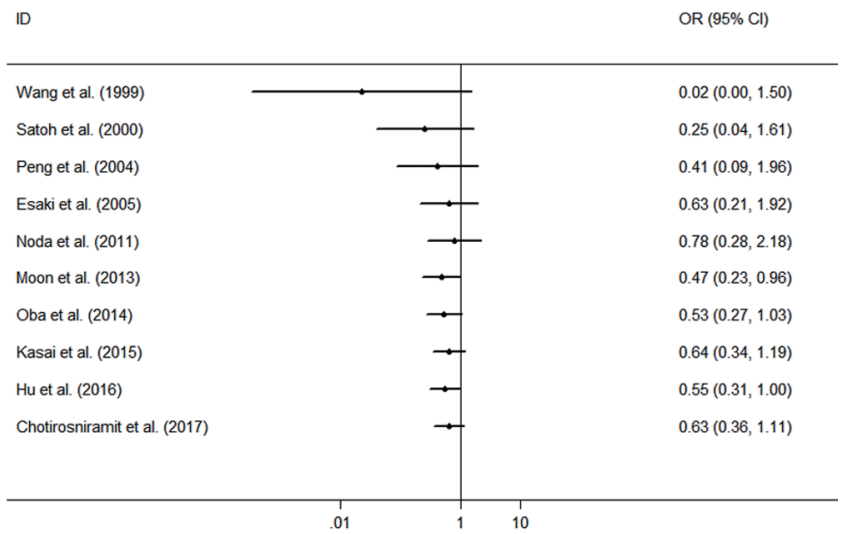

Figure 2 Forest plots of meta-analysis and cumulative meta-analysis for overall survival. (A) Forest plot of OR of 1-year overall survival; (B) cumulative meta-analysis of 1-year overall survival; (C) forest plot of OR of 3-year overall survival; (D) cumulative meta-analysis of 3-year overall survival; (E) forest plot of OR of 5-year overall survival; (F) cumulative meta-analysis of 5-year overall survival. OR, odds ratio. 
A

Study

ID

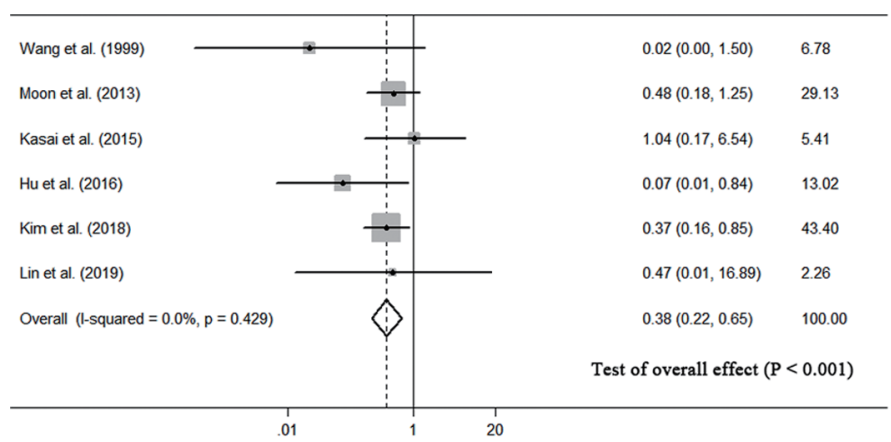

C

Study

ID

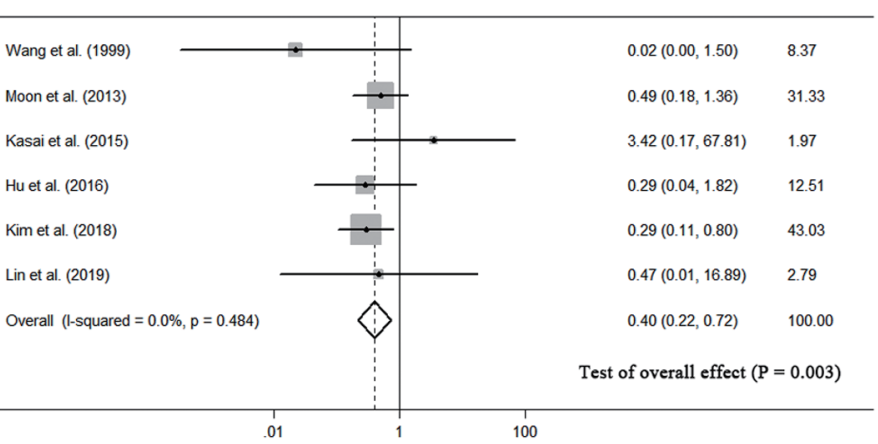

E

Study

ID

\section{Wang et al. (1999)}

Moon et al. (2013)

Kasai et al. (2015)

Hu et al. (2016)

Kim et al. (2018)

Lin et al. (2019)

Overall (1-squared $=10.4 \%, p=0.349$ )

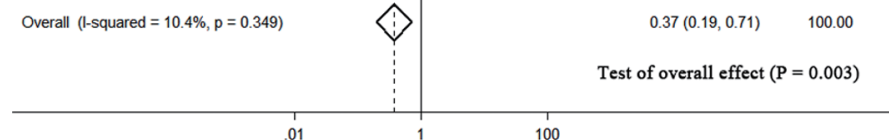

\section{B}

Study

ID

OR $(95 \% \mathrm{Cl})$

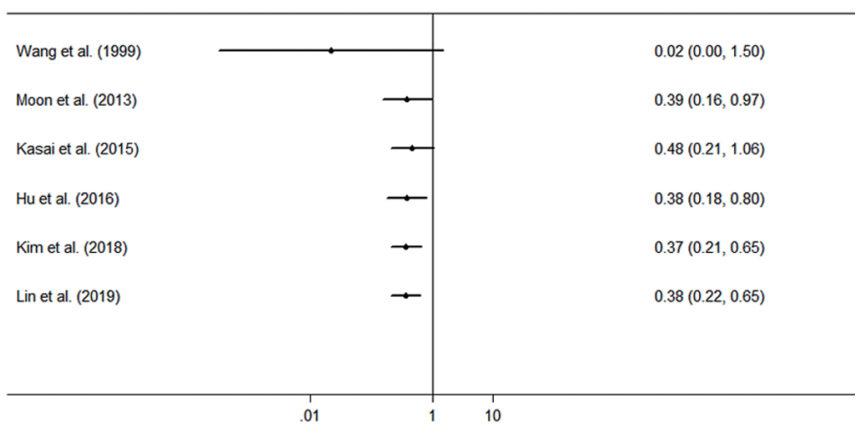

D

Study

ID $\quad$ OR $(95 \% \mathrm{Cl})$

\begin{tabular}{l|l} 
Wang et al. (1999) $\quad 0.02(0.00,1.50)$ & \\
\hdashline
\end{tabular}

Moon et al. (2013) $0.40(0.15,1.02)$

Kasai et al. (2015) $\quad-50.54(0.23,1.26)$

Hu et al. (2016) $\quad \longrightarrow \quad 0.48(0.22,1.03)$

Kim et al. (2018) $\rightarrow-0.40(0.22,0.73)$

Lin et al. (2019) $\quad \rightarrow \quad 0.40(0.22,0.72)$

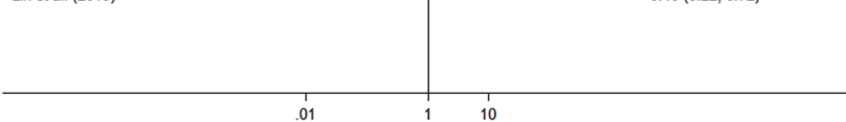

$\mathrm{F}$

Study

ID $\quad$ OR $(95 \% \mathrm{Cl})$

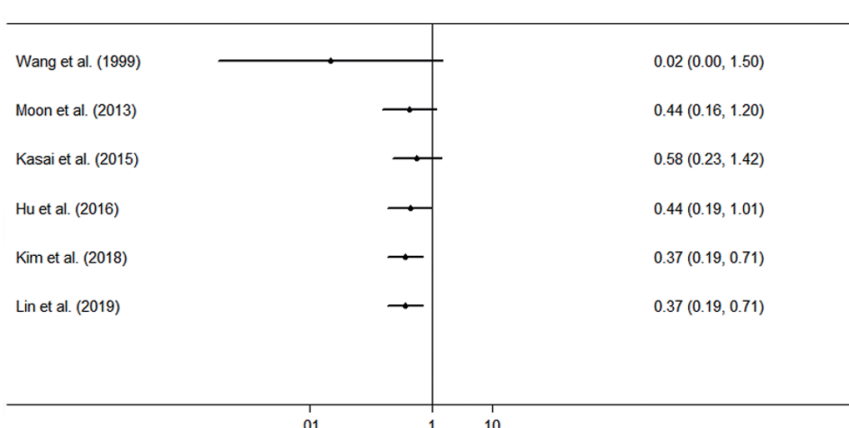

Figure 3 Forest plots of meta-analysis and cumulative meta-analysis for recurrence-free survival. (A) Forest plot of OR of 1-year recurrencefree survival; (B) cumulative meta-analysis of 1-year recurrence-free survival; (C) forest plot of OR of 3-year recurrence-free survival; (D) cumulative meta-analysis of 3-year recurrence-free survival; (E) forest plot of OR of 5-year recurrence-free survival; (F) cumulative metaanalysis of 5 -year recurrence-free survival. OR, odds ratio. 
liver failure and mortality, and as a consequence, nonsurgical modalities such as biliary drainage, transarterial chemoembolization (TACE) are commonly conducted instead. However, with the improvement in surgical techniques and perioperative management as well as a better understanding of this disease in recent years, it has been well-established that curative resection for HCC with BDTT is now a safe and effective choice. A series of studies has provided conclusive evidence that surgical resection with curative intent results in more favorable outcomes than nonsurgical treatments for patients with HCC and BDTT $(6,7,30)$. Nevertheless, there is still no consensus concerning the optimal method of surgical treatment, and the prognosis following different types of surgical intervention is controversial.

In terms of the choice of surgical modality, some authors recommend that hepatectomy plus thrombectomy via choledochotomy is sufficient to achieve radical treatment $(7,8,12,22,30-32)$. This proposition is based on the surgical and histopathological observations that BDTT does not adhere to the bile duct and can be detached readily $(20,23,29,31,32)$. Also, the risks of critical complications including liver abscess and ischemic cholangitis increase substantially after TACE or ablation therapy in patients who undergo BDR and bilioenteric anastomosis, which greatly restricts the use of loco-regional therapy to prevent future recurrence $(33,34)$. In contrast, simultaneous liver resection and BDR is strongly advocated by some investigators $(9,10,19,35)$. This procedure is recommended on the basis that tumor cells are frequently identified in the resected specimens of bile duct under the microscope, even though macroscopic BDTT seems loosely attached to the bile duct. Zeng et al. (35) reported that two-thirds of patients with HCC and BDTT had histopathological evidence of tumor involvement within the bile duct wall. Additionally, thrombectomy carries a potential risk for local recurrence at the preserved bile duct and for intraoperative peritoneal dissemination of tumor cells $(19,36,37)$.

With respect to long-term outcomes of the two groups of patients, Satoh et al. (12) and Shiomi et al. (32) concluded that there were no significant differences in OS rates between HCC patients with BDTT whether or not they underwent BDR. Moon et al. (23) investigated the outcomes of 73 HCC patients with BDTT from 4 major Institutes in Korea and reported that the rates of recurrence were not significantly different between the BDR and NBDR groups $(\mathrm{P}=0.178)$. However, other researchers have drawn different conclusions. Hu et al. (9) conducted a 1:1 well- matched study, which showed that both $\mathrm{OS}(\mathrm{P}=0.014)$ and RFS ( $\mathrm{P}=0.023)$ were superior in the BDR group. Based on a multicenter retrospective study with a large cohort of HCC patients with BDTT, Kim et al. (10) also found that the recurrence rate was notably lower in patients who underwent $\mathrm{BDR}(\mathrm{P}=0.022)$. Moreover, $\mathrm{BDR}$ was determined as an independent favorable prognostic factor for both OS (HR $=0.51,95 \%$ CI: $0.31-0.48, \mathrm{P}=0.008)$ and recurrence ( $\mathrm{HR}=0.61,95 \% \mathrm{CI}: 0.42-0.89, \mathrm{P}=0.009)$ in their study.

In the present meta-analysis, we compared the survival outcomes between the BDR and NBDR groups. The results showed that the 1-, 3- and 5-year OS rates were similar between the two groups ( $\mathrm{OR}=0.58,95 \%$ CI: $0.31-1.09$; $\mathrm{OR}$ $=0.74,95 \%$ CI: $0.43-1.28$; and OR $=0.63$, 95\% CI: $0.36-$ 1.11 , respectively), while the RFS rates were significantly better for patients who underwent additional BDR (1-year RFS: OR $=0.38,95 \%$ CI: 0.22-0.65; 3-year RFS: OR $=0.40,95 \%$ CI: $0.22-0.72$; 5 -year RFS: OR $=0.37,95 \%$ CI: $0.19-0.71)$. It is easy to understand why RFS is significantly longer and that the local recurrence rate is markedly reduced in patients with concurrent BDR, because this approach increases the chance of clearing the minute tumor deposits and micro-metastases which cannot be identified in preoperative imaging or by intraoperative exploration. As for why this does not translate into a better OS rate, we hypothesize that a possible reason could be that the potential survival benefit resulting from BDR is counteracted by the situation that the grade of BDTT is more advanced for patients receiving BDR. Their post-recurrence survival is shortened because the choice of loco-regional treatments is limited when recurrence occurs in the BDR group.

Based on the results derived from previous studies, and on the present meta-analysis, here we suggest that it is desirable to select an individual surgical plan for each patient. When BDTT is restricted to within the transection plane, it can be removed along with the primary tumor en bloc. If BDTT extends beyond resection line to extrahepatic major bile ducts but can be peeled off easily, thrombectomy through choledochotomy is the prioritized option to guarantee the possibility of applying adjuvant treatments against recurrence. When BDTT attaches tightly to the wall of the large bile duct, concurrent BDR should be preferred in order to decrease local recurrence.

Several limitations persisting in this analysis must be acknowledged. First, all the studies included in this review are retrospective observational trials with inherent selection and publication bias. Second, all the studies were conducted in Asia. Thus, the applicability of these results needs to be 
further validated in Western countries. Last, due to the rarity of this condition, most studies include only a small number of cases from one single center, which potentially influences the final conclusion.

\section{Conclusions}

In conclusion, the current meta-analysis suggests that concurrent hepatectomy and bile duct resection significantly decreases postoperative recurrence rates in the management of HCC patients with BDTT. However, the overall survival rates were similar whether or not patients underwent additional bile duct resection. Therefore, multiple factors should be evaluated to select a reasonable surgical strategy tailored to the individual patient. Importantly, more largescale, well-designed clinical trials from international centers need to be carried out in order to reach a global consensus on this matter.

\section{Acknowledgments}

The authors would like to express their gratitude to EditSprings (http://www.editsprings.com/) for the expert linguistic services provided.

Funding: This study was supported by the Key Project of Natural Science Foundation of China (No. 81730097); the Grants of the Science Fund for Creative Research Groups (No. 81521091) and the National Natural Science Foundation of China (No. 81602523).

\section{Footnote}

Reporting Checklist: The authors have completed the PRISMA reporting checklist. Available at http://dx.doi. org/10.21037/atm-20-3935

Data Sharing Statement: Available at http://dx.doi. org/10.21037/atm-20-3935

Conflicts of Interest: All authors have completed the ICMJE uniform disclosure form (available at: http://dx.doi. org/10.21037/atm-20-3935). The authors have no conflicts of interest to declare.

Ethical Statement: The authors are accountable for all aspects of the work in ensuring that questions related to the accuracy or integrity of any part of the work are appropriately investigated and resolved.
Open Access Statement: This is an Open Access article distributed in accordance with the Creative Commons Attribution-NonCommercial-NoDerivs 4.0 International License (CC BY-NC-ND 4.0), which permits the noncommercial replication and distribution of the article with the strict proviso that no changes or edits are made and the original work is properly cited (including links to both the formal publication through the relevant DOI and the license). See: https://creativecommons.org/licenses/by-nc-nd/4.0/.

\section{References}

1. Bray F, Ferlay J, Soerjomataram I, et al. Global cancer statistics 2018: GLOBOCAN estimates of incidence and mortality worldwide for 36 cancers in 185 countries. CA Cancer J Clin 2018;68:394-424.

2. Kokudo T, Hasegawa K, Yamamoto S, et al. Surgical treatment of hepatocellular carcinoma associated with hepatic vein tumor thrombosis. J Hepatol 2014;61:583-8.

3. Kokudo T, Hasegawa K, Matsuyama Y, et al. Survival benefit of liver resection for hepatocellular carcinoma associated with portal vein invasion. J Hepatol 2016;65:938-43.

4. Wang DD, Wu LQ, Wang ZS. Prognosis of hepatocellular carcinoma with bile duct tumor thrombus after R0 resection: a matched study. Hepatobiliary Pancreat Dis Int 2016;15:626-32.

5. Orimo T, Kamiyama T, Yokoo H, et al. Hepatectomy for hepatocellular carcinoma with bile duct tumor thrombus, including cases with obstructive jaundice. Ann Surg Oncol 2016;23:2627-34.

6. An J, Lee KS, Kim KM, et al. Clinical features and outcomes of patients with hepatocellular carcinoma complicated with bile duct invasion. Clin Mol Hepatol 2017;23:160-9.

7. Oba A, Takahashi S, Kato Y, et al. Usefulness of resection for hepatocellular carcinoma with macroscopic bile duct tumor thrombus. Anticancer Res 2014;34:4367-72.

8. Kasai Y, Hatano E, Seo S, et al. Hepatocellular carcinoma with bile duct tumor thrombus: surgical outcomes and the prognostic impact of concomitant major vascular invasion. World J Surg 2015;39:1485-93.

9. Hu XG, Mao W, Hong SY, et al. Surgical treatment for hepatocellular carcinoma with bile duct invasion. Ann Surg Treat Res 2016;90:139-46.

10. Kim DS, Kim BW, Hatano E, et al. Surgical outcomes of hepatocellular carcinoma with bile duct tumor thrombus: a Korea-Japan multicenter study. Ann Surg 2020;271:913-21.

11. Moher D, Liberati A, Tetzlaff J, et al. Preferred reporting items for systematic reviews and meta-analyses: the 
PRISMA statement. BMJ 2009;339:b2535.

12. Satoh S, Ikai I, Honda G, et al. Clinicopathologic evaluation of hepatocellular carcinoma with bile duct thrombi. Surgery 2000;128:779-83.

13. Ueda M, Takeuchi T, Takayasu T, et al. Classification and surgical treatment of hepatocellular carcinoma (HCC) with bile duct thrombi. Hepatogastroenterology 1994;41:349-54.

14. Kudo M, Kitano M, Sakurai T, et al. General rules for the clinical and pathological study of primary liver cancer, nationwide follow-up survey and clinical practice guidelines: the outstanding achievements of the Liver Cancer Study Group of Japan. Dig Dis 2015;33:765-70.

15. Higgins JP, Altman DG, Gøtzsche PC, et al. The Cochrane Collaboration's tool for assessing risk of bias in randomised trials. BMJ 2011;343:d5928.

16. Stang A. Critical evaluation of the Newcastle-Ottawa scale for the assessment of the quality of nonrandomized studies in meta-analyses. Eur J Epidemiol 2010;25:603-5.

17. Higgins JP, Thompson SG, Deeks JJ, et al. Measuring inconsistency in meta-analyses. BMJ 2003;327:557-60.

18. Sutton AJ, Duval SJ, Tweedie RL, et al. Empirical assessment of effect of publication bias on meta-analyses. BMJ 2000;320:1574-7.

19. Wang HJ, Kim JH, Kim JH, et al. Hepatocellular carcinoma with tumor thrombi in the bile duct. Hepatogastroenterology 1999;46:2495-9.

20. Peng SY, Wang JW, Liu YB, et al. Surgical intervention for obstructive jaundice due to biliary tumor thrombus in hepatocellular carcinoma. World J Surg 2004;28:43-6.

21. Esaki M, Shimada K, Sano T, et al. Surgical results for hepatocellular carcinoma with bile duct invasion: a clinicopathologic comparison between macroscopic and microscopic tumor thrombus. J Surg Oncol 2005;90:226-32.

22. Noda T, Nagano H, Tomimaru Y, et al. Prognosis of hepatocellular carcinoma with biliary tumor thrombi after liver surgery. Surgery 2011;149:371-7.

23. Moon DB, Hwang S, Wang HJ, et al. Surgical outcomes of hepatocellular carcinoma with bile duct tumor thrombus: a Korean multicenter study. World J Surg 2013;37:443-51.

24. Chotirosniramit A, Liwattanakun A, Lapisatepun W, et al. A single institution report of 19 hepatocellular carcinoma patients with bile duct tumor thrombus. J Hepatocell Carcinoma 2017;4:41-7.

25. Lin Z, Han M, Zhou Z. Prognosis for patients with hepatocellular carcinoma (HCC) with bile duct tumor thrombus (BDTT) after surgical treatment. Biosci Trends 2019;13:77-85.

26. Lin TY, Chen KM, Chen YR, et al. Icteric type hepatoma.
Med Chir Dig 1975;4:267-70.

27. Lau W, Leung K, Leung TW, et al. A logical approach to hepatocellular carcinoma presenting with jaundice. Ann Surg 1997;225:281-5.

28. Ikenaga N, Chijiiwa K, Otani K, et al. Clinicopathologic characteristics of hepatocellular carcinoma with bile duct invasion. J Gastrointest Surg 2009;13:492-7.

29. Yu XH, Xu LB, Liu C, et al. Clinicopathological characteristics of 20 cases of hepatocellular carcinoma with bile duct tumor thrombi. Dig Dis Sci 2011;56:252-9.

30. Xiangji L, Weifeng T, Bin Y, et al. Surgery of hepatocellular carcinoma complicated with cancer thrombi in bile duct: efficacy for criteria for different therapy modalities. Langenbecks Arch Surg 2009;394:1033-9.

31. Yamamoto S, Hasegawa K, Inoue Y, et al. Bile duct preserving surgery for hepatocellular carcinoma with bile duct tumor thrombus. Ann Surg 2015;261:e123-5.

32. Shiomi M, Kamiya J, Nagino M, et al. Hepatocellular carcinoma with biliary tumor thrombi: aggressive operative approach after appropriate preoperative management. Surgery 2001;129:692-8.

33. Woo S, Chung JW, Hur S, et al. Liver abscess after transarterial chemoembolization in patients with bilioenteric anastomosis: frequency and risk factors. AJR Am J Roentgenol 2013;200:1370-7.

34. Hoffmann R, Rempp H, Schmidt D, et al. Prolonged antibiotic prophylaxis in patients with bilioenteric anastomosis undergoing percutaneous radiofrequency ablation. J Vasc Interv Radiol 2012;23:545-51.

35. Zeng H, Xu LB, Wen JM, et al. Hepatocellular carcinoma with bile duct tumor thrombus: a clinicopathological analysis of factors predictive of recurrence and outcome after surgery. Medicine (Baltimore) 2015;94:e364.

36. Mok KT, Chang HT, Liu SI, et al. Surgical treatment of hepatocellular carcinoma with biliary tumor thrombi. Int Surg 1996;81:284-8.

37. Xu LB, Liu C. Hepatocellular carcinoma with bile duct tumor thrombus: extrahepatic bile duct preserving or not? Ann Surg 2017;266:e62-3.

Cite this article as: Feng JK, Chen $\mathrm{ZH}, \mathrm{Wu} \mathrm{YX}$, Wang $\mathrm{K}$, Sun JX, Chai ZT, Guo WX, Shi J, Cheng SQ. Comparison of different surgical interventions for hepatocellular carcinoma with bile duct tumor thrombus: a systematic review and metaanalysis. Ann Transl Med 2020;8(23):1567. doi: 10.21037/atm20-3935 


\section{Supplementary}

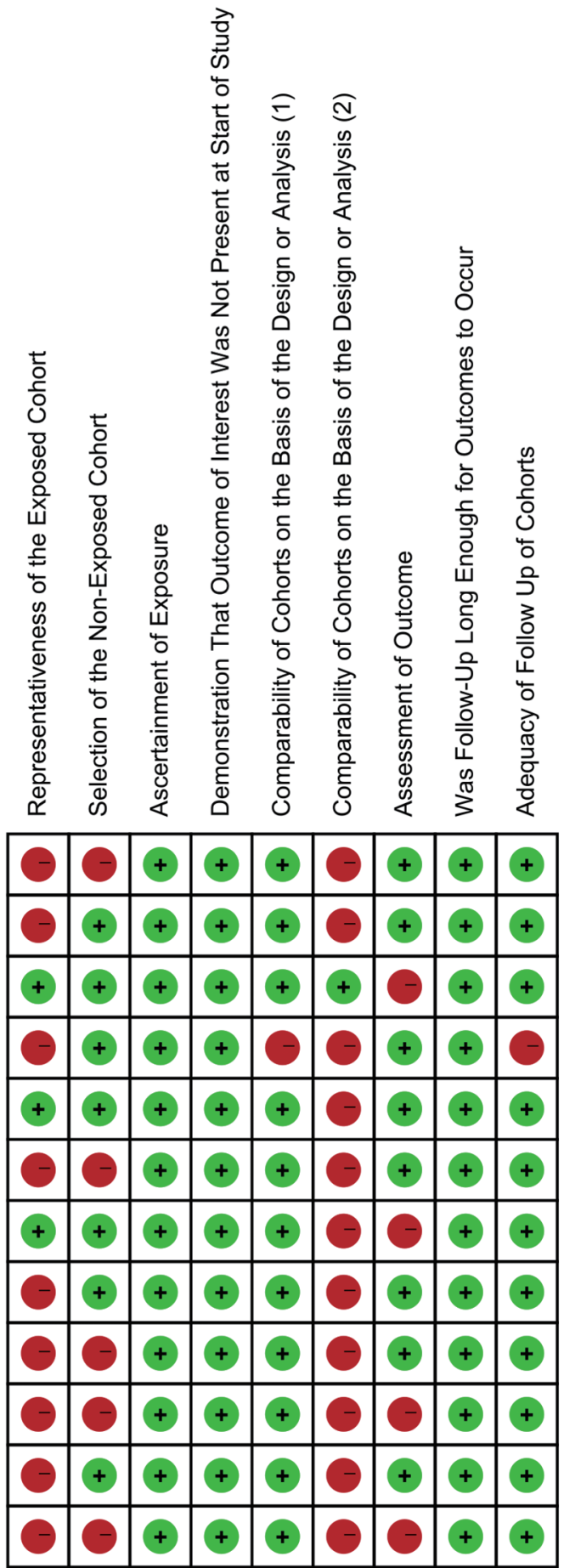

Figure S1 Risk of bias summary of the included studies according to the modified Newcastle-Ottawa Scale. 


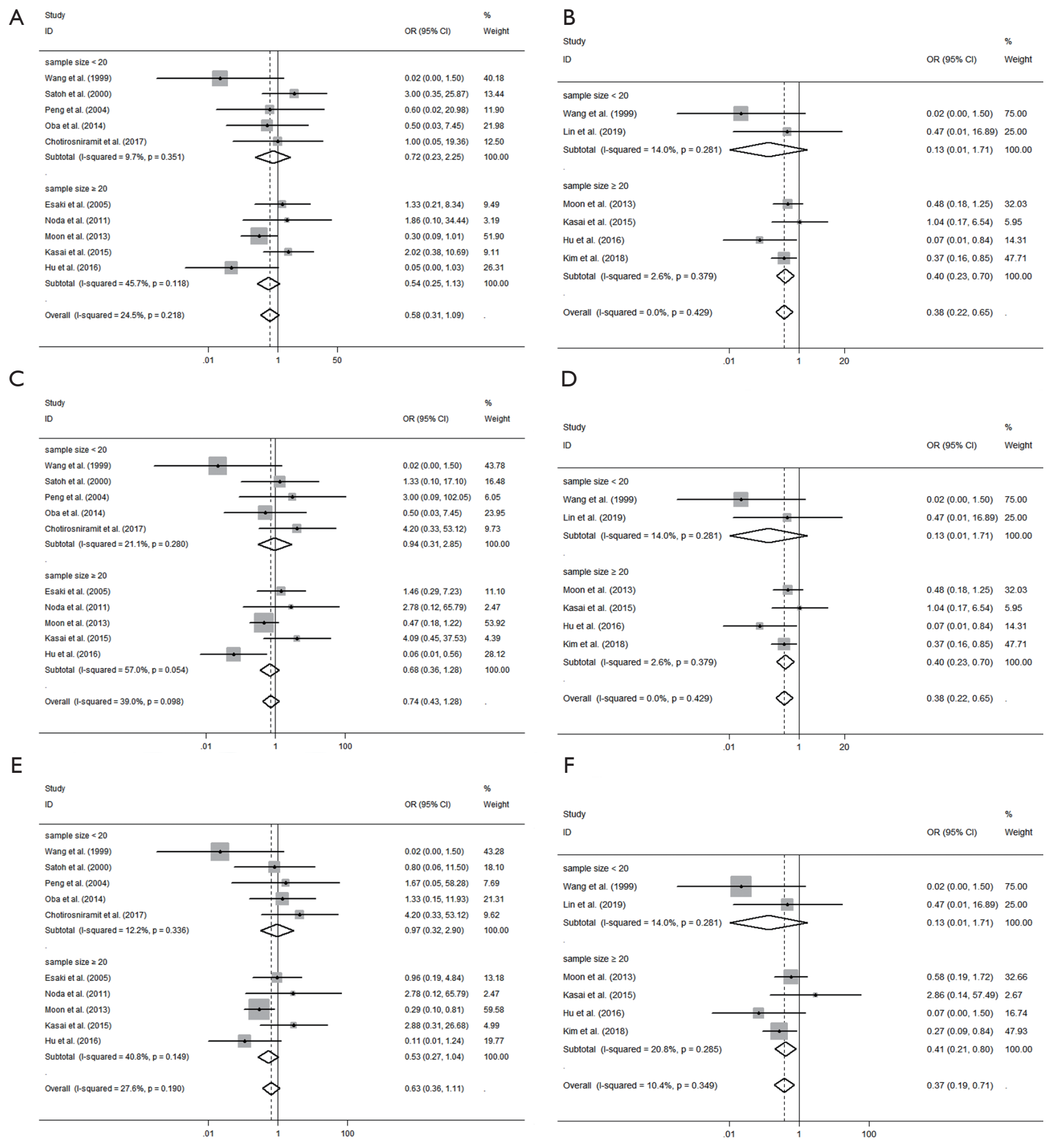

Figure S2 Forest plots of subgroup analysis according to overall sample size ( $<20 \mathrm{vs.} \geq 20)$ for overall survival and recurrence-free survival. (A) Forest plot of OR of 1-year overall survival; (B) forest plot of OR of 1-year recurrence-free survival; (C) forest plot of OR of 3-year overall survival; (D) forest plot of OR of 3-year recurrence-free survival; (E) forest plot of OR of 5-year overall survival; (F) forest plot of OR of 5-year recurrence-free survival. 
A

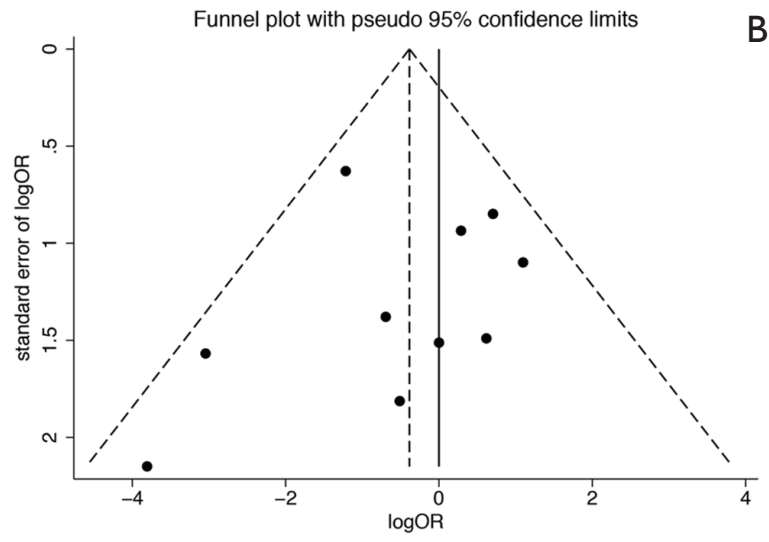

C

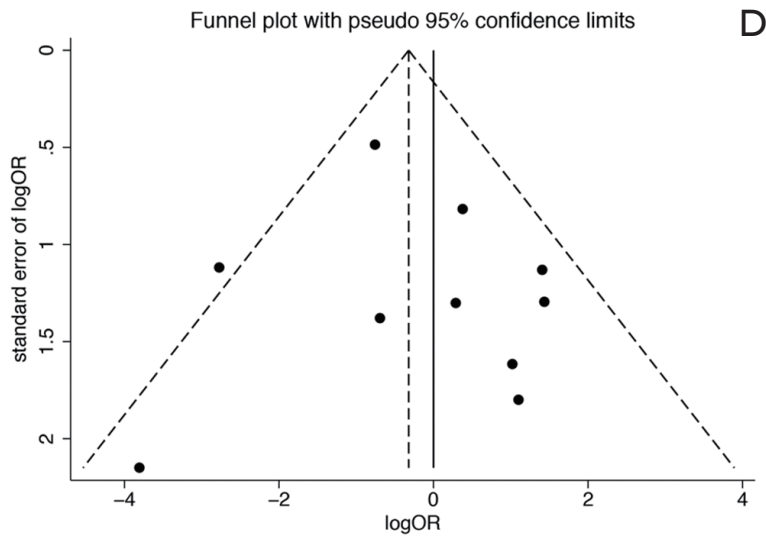

E

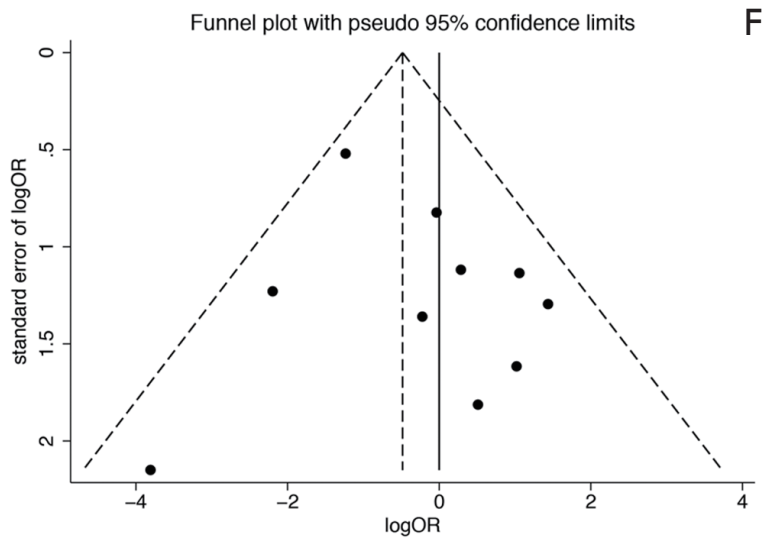

B

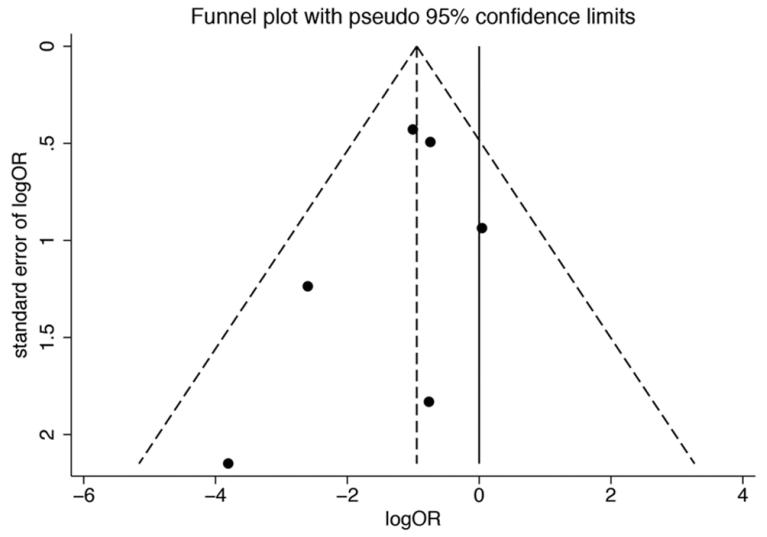

D

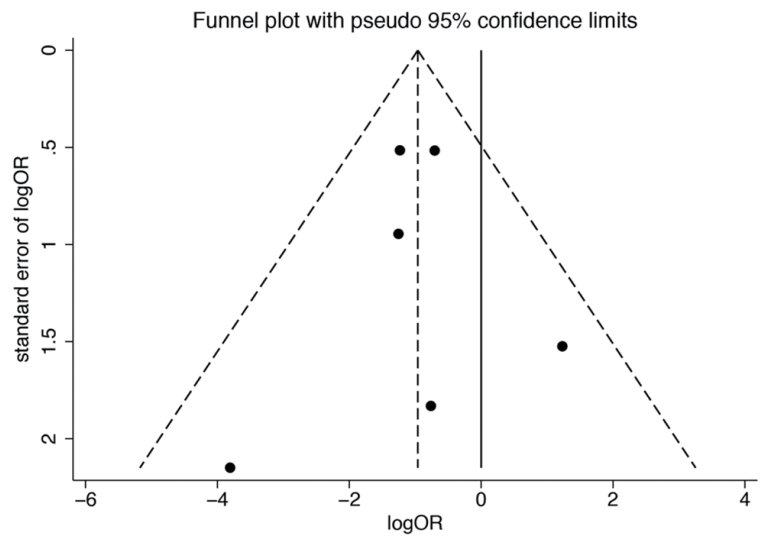

F

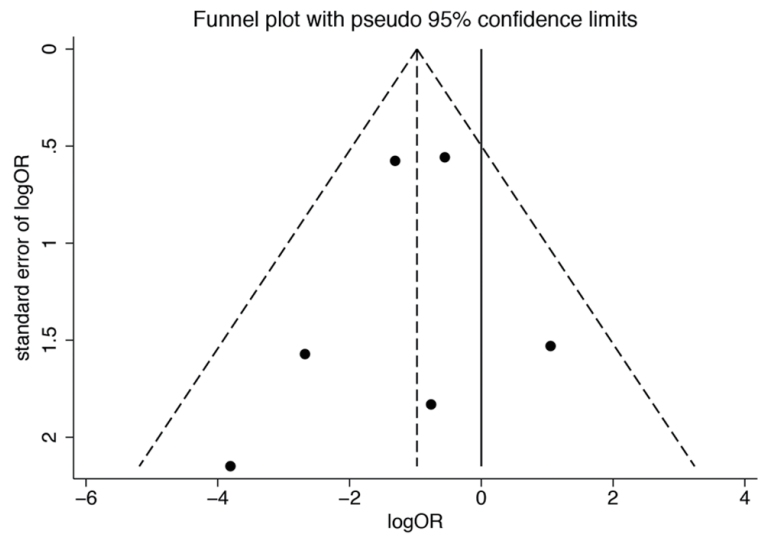

\section{G}

1-year OS 3-year OS

5-year OS

1-year RFS

3-year RFS

5-year RFS

\begin{tabular}{lcccccc} 
Number of studies & 10 & 10 & 10 & 6 & 6 & 6 \\
P value for Begg's test & 0.152 & 0.721 & 1.000 & 0.707 & 1.000 & 0.260 \\
P value for Egger's test & 0.661 & 0.660 & 0.406 & 0.375 & 0.932 & 0.613 \\
\hline
\end{tabular}

Figure S3 Publication bias of the included studies for overall survival and recurrence-free survival. (A) Funnel plot of 1-year overall survival; (B) funnel plot of 1-year recurrence-free survival; (C) funnel plot of 3-year overall survival; (D) funnel plot of 3-year recurrence-free survival; (E) funnel plot of 5-year overall survival; (F) funnel plot of 5-year recurrence-free survival; (G) quantitative assessment for publication bias. 
A

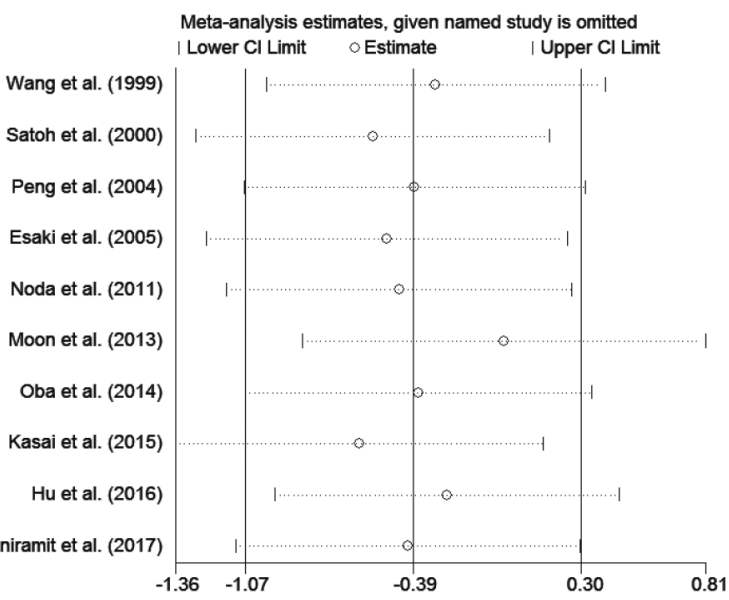

C

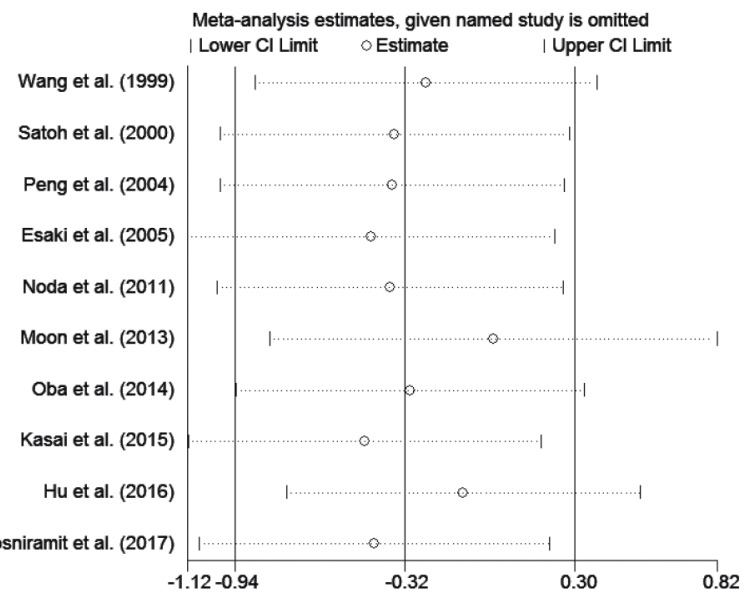

$\mathrm{E}$

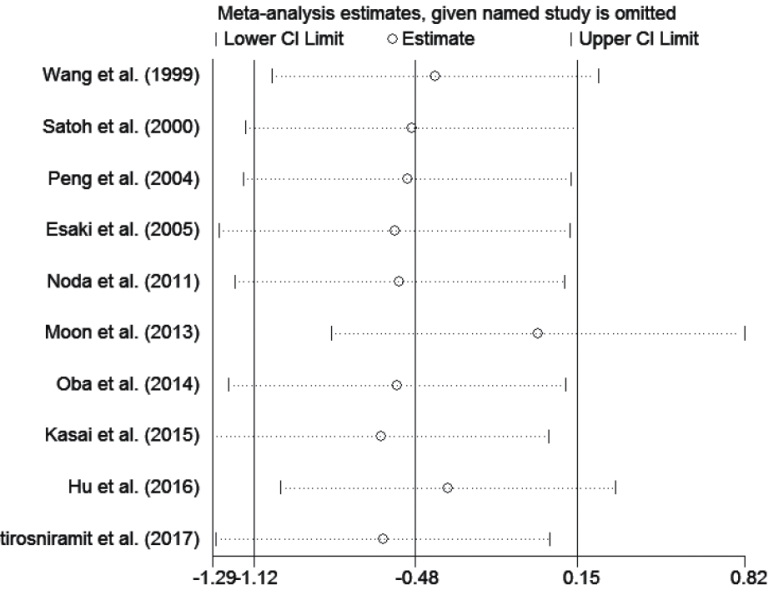

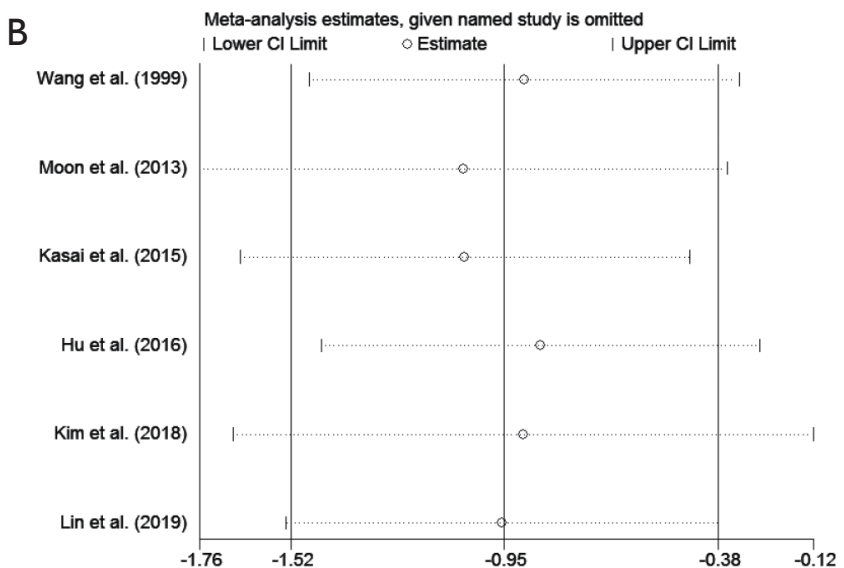

D

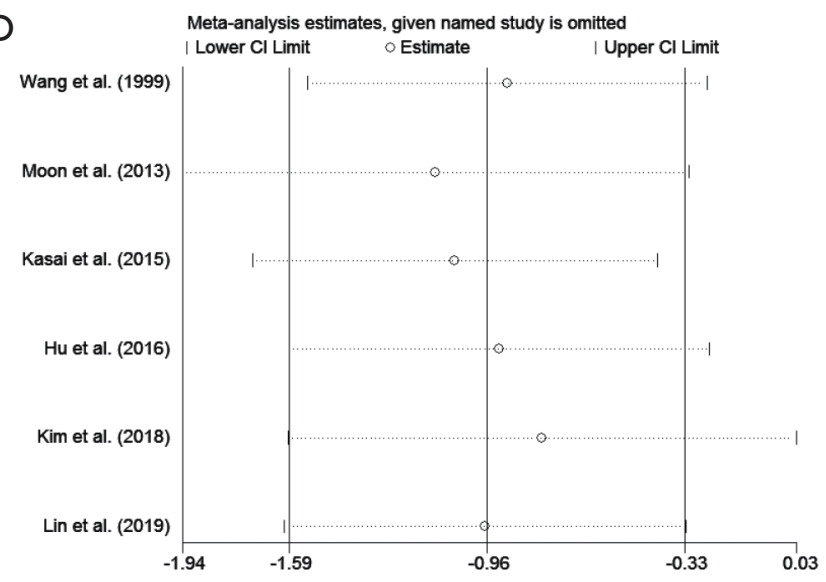

F

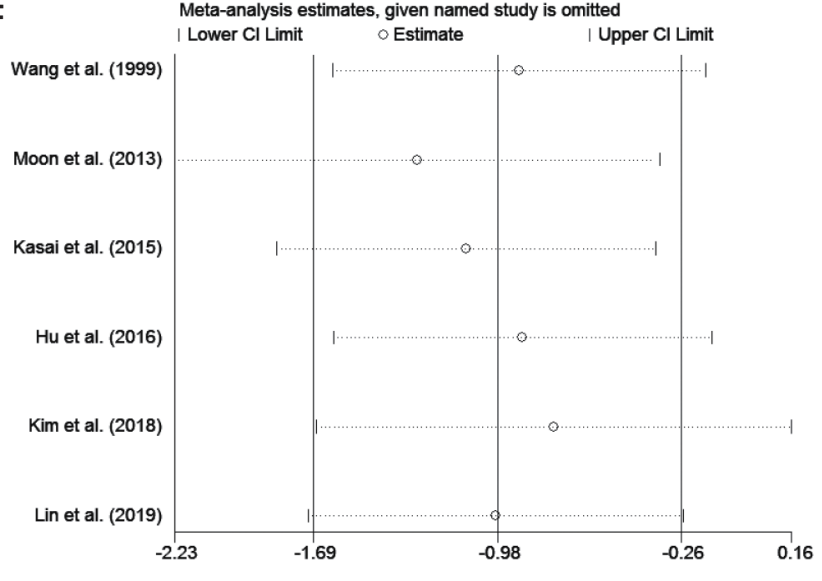

Figure S4 Sensitivity analysis for the evaluation of potential heterogeneity of all the outcomes. (A) sensitivity analysis of 1-year overall survival; (B) sensitivity analysis of 1-year recurrence-free survival; (C) sensitivity analysis of 3-year overall survival; (D) sensitivity analysis of 3-year recurrence-free survival; (E) sensitivity analysis of 5-year overall survival; (F) sensitivity analysis of 5-year recurrence-free survival. 